\title{
PENGARUH PENAMBAHAN UNSUR MOLIBDENUM (Mo) TERHADAP SIFAT MEKANIK DAN STRUKTUR MIKRO PADA BAJA TAHAN KARAT TIPE AISI 410
}

\author{
Sujianto ${ }^{1}$ \\ ${ }^{1}$ Program Studi Teknik Mesin, Universitas Pamulang, Jl. Surya Kencana No. 1, Tangerang Selatan, Indonesia \\ Email : dosen01286@unpam.ac.id
}

Masuk : 10 Marei 2019 Direvisi : 24 Maret 2019 Disetujui : 10 April 2019

\begin{abstract}
Abstrak: Turbin uap merupakan salah satu pembangkit listrik yang menjadi salah satu pilihan untuk saat ini. Ada beberapa komponen turbin uap yang sering terjadi kegagalan . Diantaranya adalah komponen sudu sudu turbin uap. Pada komponen sudu sudu turbin uap dipilih menggunakan material baja tahan karat martensitik AISI 410 disebabkan memiliki kekuatan tinggi, ketangguhan tinggi dan ketahanan korosi. Penelitian berikut memaparkan pengaruh penaambahan unsur Mo terhadap struktur mikro dan Sifat mekanik baja tahan karat AISI 410 dengan kondisi suhu tempering pada $600^{\circ} \mathrm{C}, 650^{\circ} \mathrm{C}, 700^{\circ} \mathrm{C}$. Maksud dan tujuan penelitian ini adalah untuk menganalisa sifat mekanik : Kukuatan tarik, serta menganalisa perubahan nilai kekerasan dan struktur mikro pada baja tahan karat AISI 410. Penelitian ini menggunakan sampel material uji AISI 410 Standar dan AISI 410 yang telah dimodifikasi dengan penambahan unsur Moliibdenum (Mo) 3 $\%$, proses awal yakni austenisasi pada temperatur $1050^{\circ} \mathrm{C}$ selama 1 jam di dalam tungku muffle dan didinginkan dengan udara bebas . Dengan temperisasi pada $600^{\circ} \mathrm{C}, 650^{\circ} \mathrm{C}, 700^{\circ} \mathrm{C}$ dengan variasi waktu $1,3,6$ jam. Pengamatan struktur mikro dilakukan menggunakan mikroskop, uji komposisi kimia, SEM-EDS dan pengujian kekerasan dengan metode Rockwell C. Penambahan unsur Mo ke dalam baja tahan karat AISI 410 meningkatkan kandungan fasa ferit delta di dalam struktur mikro dan menurunkan kekerasan baja yang bersangkutan. Penambahan unsur 3 \% Mo menurunkan kandungan Crom di dalam karbida logam tersebut akibat subtitusi parsial Crom dengan Mo. Dengan penambahan unsur 3\% Mo juga meningkatan ketahanan terhadap korosi.
\end{abstract}

Kata kunci: Turbin Uap,Baja tahan karat martensitik 13 Cr, Molibdenum,Fasa ferit delta, kekerasan.

Abstract: Steam turbine is one of a power plant that as an option to now.Several components a steam turbine is prone to failure.one of them is a steam turbine blade components.In turbine blades components made of material rust resilient steel martensitic AISI 410, This research sets forth the influence of Molybdenum element to structure micro and mechanical properties stainless steel martensitik AISI 410 with conditions of temperature tempering at $600^{\circ} \mathrm{C}, 650^{\circ} \mathrm{C}, 700^{\circ} \mathrm{C}$. Intents and purposes this research is to analyze the mechanical properties: Ultimate tensile strength, and analyze changes in the value of violence and micro structure on aisi 410. stainless steel. This study using a sample test material aisi 410 standards and aisi 410 who has been modified with the addition of molybdenum ( Mo ) $3 \%$, the initial process namely austenisasi at temperatures $1050^{\circ} \mathrm{C}$ throughout 1 hours in a furnace muffle and cooled with air free. With temperisasi on $600^{\circ} \mathrm{C}, 650^{\circ} \mathrm{C}, 700^{\circ} \mathrm{C}$ with the variation of time 1,3,6 an hour and a half .Of the observation of the structure of development of the government micro carried out using a microscope optical the test and been approved the chemical composition , sem-eds and test it violence with that is rockwell $C$. The addition of Mo to in steel resistant to rust martensitik AISI 410 raising the standard of living in phase and their offspring and what ferrite toroid delta located on in the structure of micro and sent down need to resort to violence a steel that it to relevant national authorities. The addition of $3 \%$ mo sent down the moisture content of $\mathrm{cr}$ in carbide metal delay was caused by subtitusi partial cr with mo.dengan the addition of the elements $3 \%$ Mo also improving resistance to corrosion ..

Keywords : Steam Turbine,13 Cr martensitic stainless steels, Molybdenum, Delta ferrite,Hardness 


\section{PENDAHULUAN}

Logam Ferro merupakan unsur yang sangat diperlukan di dalam dunia industri dan manufaktur. Karena hampir semua alat alat bertegnologi tinggi menggunakan logam ferro. Alasanya ialah besi dan baja merupakan unsur yang memiliki sifat konduktor, sifat mekanik yang ulet, kuat, logam ferro juga memiliki ketahanan aus. Dalam proses pembuatan komponen sudu turbin yang sering digunakan adalah material baja tahan karat martensit AISI 410 karena mempunyai sifat tangguh dan tahan terhadap korosi yang baik. Sudu turbin merupakan bagian yang sangat penting di dalam pembangkit listrik tenaga uap. Selain berfungsi mengubah aliran uap menjadi energi gerak yang kemudian digunakan untuk menggerakan poros turbin ,sudu sudu turbin beroperasi pada putaran yang cukup tinggi sehingga kondisi seperti ini rentan terjadi kegagalan. Akibatnya sering terjadi kerusakan pada sudu turbin uap yang terjadi akibat perpaduan mekanik dan korosi. Jenis korosi sumuran, fatik korosi dan korosi retak tegang adalah mekanisme penyumbang kegagalan sudu sudu turbin uap. Cara meningkatkan sifat ketahanan dan umur pakai sudu turbin uap bisa dengan penambahan unsur lain. Salah satu pola yang bisa dilakukan adalah dengan menambahkan unsur molibdenum agar dapat meningkatkan sifat mekanik dan ketahanan korosi. Penambahan 3 \% Mo dan dilakukan perlakuan panas menjadi opsi yang dipilih para peneliti saat ini.

\section{METODOLOGI}

Dibuat 2 sampel dengan komposisi yang berbeda dengan kandungan AISI 410 standar dan penambahan unsur Mo 3 persen. Kedua sampel tersebut dibuat berukuran 50 x 50 x $200 \mathrm{~mm}$ dengan tungku peleburan induksi. Kedua sampel dilakukan proses persiapan penempaan panas pada suhu awal $1125{ }^{\circ} \mathrm{C}$ dengan menggunakan bahan bakar elpiji. Selanjutnya dilakukan proses tempa /forging hingga menghasilkan bilet dengan ukuran sekitar 30 × 30 × $300 \mathrm{~mm}$. Setelah proses penempaan keempat bilet baja dipotong sehingga memiliki tebal $10 \mathrm{~mm}$ untuk digunakan sebagai sampel uji komposisi kimia dan hasilnya disajikan pada Tabel 1. Proses terakhir adalah dengan heat treatment pada temperatur $1000{ }^{\circ} \mathrm{C}$ selama 60 menit di dalam tungku muffle dan dilanjukan dengan proses pendinginan udara.

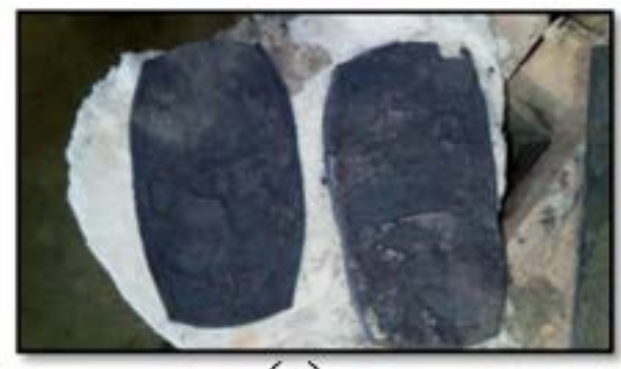

(a)

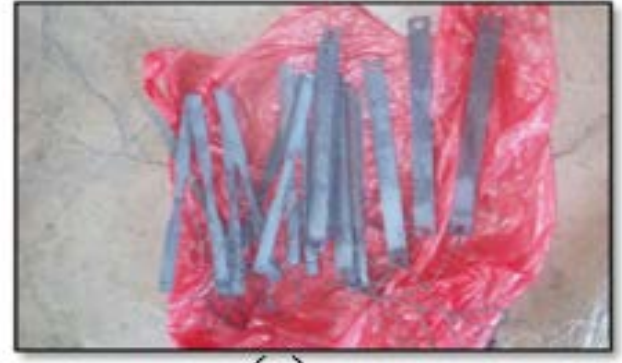

(c)

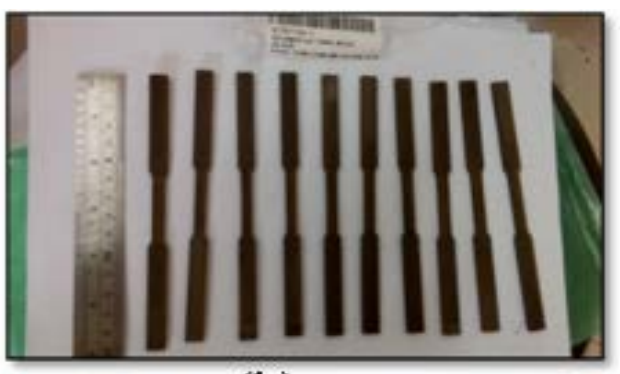

(b)

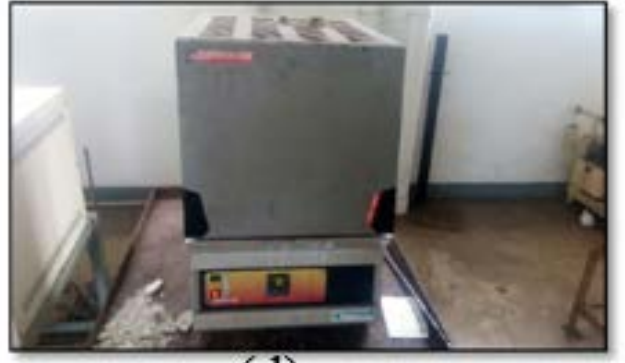

(d)

Gambar 1 (a). Ingot AISI 410 dan Modifikasi (b Specimen uji tarik dengan wire cut (c) Specimen setelah proses Austenisasi (d) Tungku carbolite

Kemudian kedua sampel baja tersebut dilakukan proses temperisasi variasi suhu $600{ }^{0} \mathrm{C}, 650{ }^{0} \mathrm{C}, 700{ }^{0} \mathrm{C}$ selama 1,3,6 jam dan di dinginkan di udara terbuka. Proses berikutnya dilakukan pengamplasan sampai permukaan halus sebelum dilakukan pengujian struktur mikro dan pengujian kekerasan metode Rockwell C. Prosedur stándar yang terdiri dari grinding (Pengrindaan) dari ukuran yang kasar ke yang halus secara bertahap, polishing (Pemolesan) dan etching menggunakan cairan nital komposisi 2\%. Proses akhir dilakukan pengujian SEM dan EDS. 


\section{HASIL DAN PEMBAHASAN}

Tabel 1 Data perbandingan pengujian komposisi kimia Baja AISI 410 modifikasi penambahan Mo 3 \% dan standart literatur.

\begin{tabular}{|l|c|c|c|c|c|c|c|c|c|}
\hline \multicolumn{1}{|c|}{ Jenis Material } & $\mathrm{C}$ & $\mathrm{Mn}$ & $\mathrm{P}$ & $\mathrm{S}$ & $\mathrm{Si}$ & $\mathrm{Cr}$ & $\mathrm{Mo}$ & $\mathrm{Ni}$ & $\mathrm{Fe}$ \\
\hline Materia Standar sesual Literatur & $0.08-0.15$ & 1 & 0.04 & 0.03 & 1 & $11.5-13$ & - & $\cdot$ & $\mathrm{Bal}$ \\
\hline Materia Specimen yang dil uji & 0.07 & 0.29 & 0.21 & 0.04 & 0.44 & 10.93 & - & 0.29 & $\mathrm{Bal}$ \\
\hline Material yang dimodifikasi Mo $3 \%$ & 0.14 & 0.99 & 0.01 & 0.001 & 0.31 & 12.94 & 2.64 & & $\mathrm{Bal}$ \\
\hline
\end{tabular}

Dengan mengamati gambar 1 maka struktur mikro yang terbentuk pada saat sebelum di modifikasi 3\% (Mo) secara dominan terbentuk struktur mikro martensit temper yang mengindikasikan material tersebut mengalami proses tempering. Dengan proses Temper $600{ }^{\circ} \mathrm{C}, 650{ }^{\circ} \mathrm{C}, 700{ }^{0} \mathrm{C}$ selama 1,3,6 meningkatkan keuletan dengan struktur mikro martensit yang berbentuk bilah (lath). Dampak yang terjadi setelah Baja AISI 410 di modifikasi dengan penambahan $3 \%$ Mo pada gambar 2 menunjukan pembesaran bilah martensit dan peningkatan fraksi ferit delta.

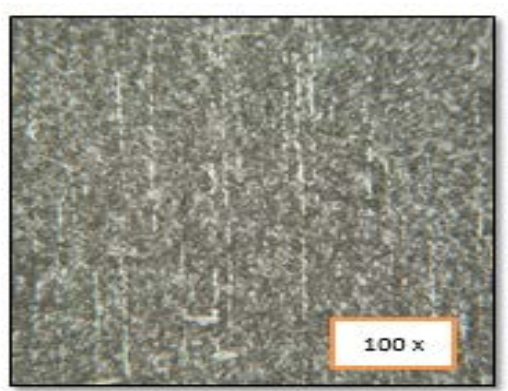

[a]

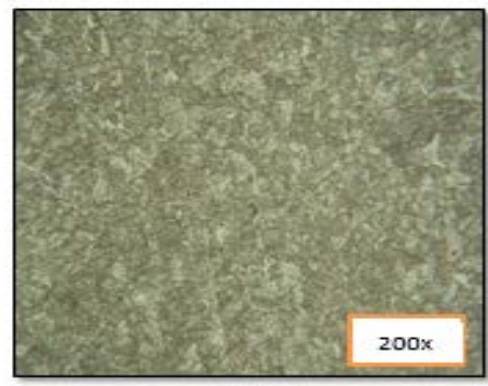

(b)

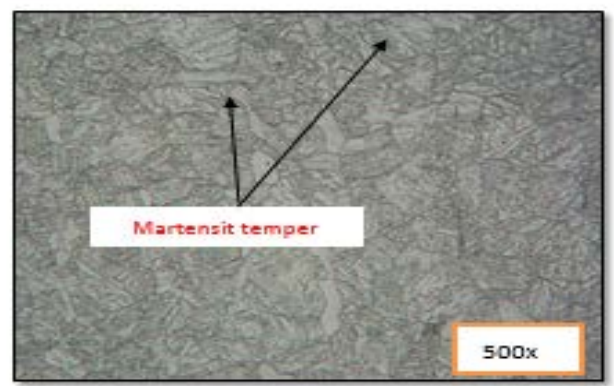

(c)

Gambar 1 Foto struktur mikro baja AISI 410 Standar yang dilakukan dengan Etsa Kalling's pada austenisasi $1050{ }^{0} \mathrm{C}$ dan proses tempering $650{ }^{\circ} \mathrm{C}$ selama 3 jam didinginkan dengan udara.(a) Pembesaran 100x (b) Pembesaran $200 \mathrm{x}$ (c) Pembesaran 500x. 


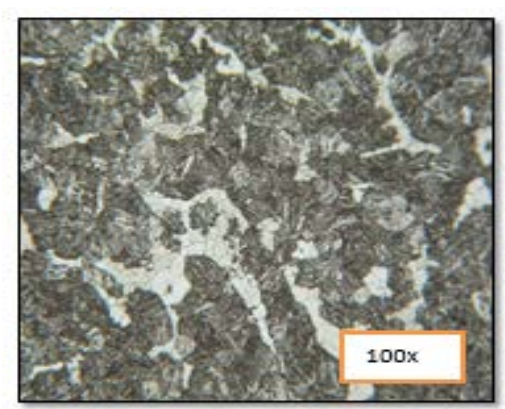

(a)

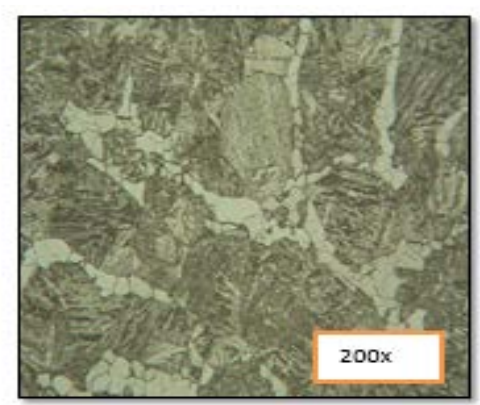

(b)

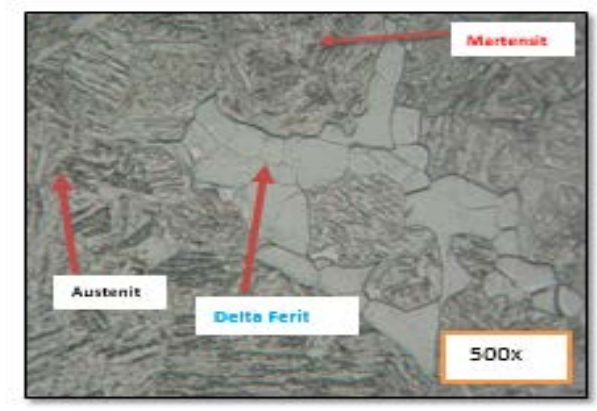

(c)

Gambar 2 Foto struktur mikro baja AISI 410 Modifikasi 3\% (Mo) yang dilakukan dengan Etsa Kalling’s pada austenisasi $1050{ }^{\circ} \mathrm{C}$ dan proses tempering $650{ }^{\circ} \mathrm{C}$ selama 3 jam didinginkan dengan udara.(a) Pembesaran 100x (b) Pembesaran $200 \mathrm{x}$ (c) Pembesaran 500x.

Tabel 2 Data pengujian kekerasan Rockwell Baja AISI 410 standart setelah proses tempering $600{ }^{\circ} \mathrm{C}, 650{ }^{0} \mathrm{C}, 700{ }^{\circ} \mathrm{C}$ selama 1,3,6 jam pendinginan udara.

\begin{tabular}{|l|c|c|c|}
\hline waktu suhu & $600^{\circ} \mathrm{C}$ & $650^{\circ} \mathrm{C}$ & $700^{\circ} \mathrm{C}$ \\
\hline $1 \mathrm{jam}$ & 57.1 & 57 & 46.1 \\
\hline $3 \mathrm{Jam}$ & 48.3 & 43.2 & 41.2 \\
\hline $6 \mathrm{jam}$ & 43.6 & 43.4 & 38.1 \\
\hline
\end{tabular}

Tabel 2 menunjukan perbandingan nilai kekerasan baja AISI 410 tanpa (Mo) dengan proses temper yang berbeda dengan proses Austenisasi sama yaitu $1050{ }^{\circ} \mathrm{C}$ selama 1 jam. Secara umum mengalami kekerasan yang menurun ini akibat proses temper . Hal ini menjadi alasan wajar jika keuletan miningkat berdampak kekerasan material menurun baik dengan proses tempering 1 jam, 3 jam, 6 jam.

Tabel 3 Data pengujian kekerasan Baja AISI 410 Modifikasi.

\begin{tabular}{|c|c|c|c|}
\hline $\begin{array}{ll}\text { waktu } & \text { Suhu } \\
\end{array}$ & $6^{\circ} \mathrm{C}$ & $650^{\circ} \mathrm{C}$ & $700^{\circ} \mathrm{C}$ \\
\hline 1 jam & 62 & 62.1 & 61.4 \\
\hline 3 Jam & 48 & 38.7 & 34.6 \\
\hline 6 jam & 54 & 59.8 & 48.1 \\
\hline
\end{tabular}

Pada tabel 2 menunjukan kekerasan baja AISI 410 yang telah di modifikasi dengan penambahan 3 \% (Mo). Pada umumnya semakin tinggi temperatur maka semakin mudah karbon berdifusi berakibat baja tahan karat semakin ulet dan berkurang 
kekerasanya ini telihat jelas pada tabel 3. Namun ada fenomena yang berbeda pada proses temper yang 6 jam justru pada saat suhu temper $650{ }^{\circ} \mathrm{C}$ terjadi peningkatan nilai kekerasan dari $54 \mathrm{HRC}$ menjadi 59,8 HRC. Pada suhu 500-650 ${ }^{0} \mathrm{C}$ akan terbentuk karbida logam akibat paduan antara kromium dan molibdenum yang menyebabkan peningkatan kekerasan. Pada suhu temperisasi $700{ }^{0} \mathrm{C}$ terjadi penurunan sifat kekerasan kembali disebabkan peningkatan relaksasi struktur fasa martensit menjadi martensit temper dan mengalami perubahan ukuran butir karbida (coarsening).

Tabel 4 Data pengujian Tarik Baja AISI 410 Standart . Data pengujian Tarik Baja AISI 410 Modifikasi penambahan 3 \% (Mo)

\begin{tabular}{|c|c|c|c|c|c|c|}
\hline Suhu Tempering & \multicolumn{2}{|c|}{$\mathbf{6 0 0}^{\circ} \mathbf{C}$} & \multicolumn{2}{c|}{$\mathbf{6 5 0}^{\circ} \mathbf{C}$} & \multicolumn{2}{c|}{$700{ }^{\circ} \mathbf{C}$} \\
\hline Waktu Tempering & Standart & Modifikasi & Standart & Modifikasi & Standart & Modifikasi \\
\hline 1 Jam & $1330 \mathrm{Mpa}$ & $1350 \mathrm{Mpa}$ & $1350 \mathrm{Mpa}$ & $1340 \mathrm{Mpa}$ & $989 \mathrm{Mpa}$ & $1020 \mathrm{Mpa}$ \\
\hline 3 Jam & $1010 \mathrm{Mpa}$ & $1080 \mathrm{Mpa}$ & $945 \mathrm{Mpa}$ & $1110 \mathrm{Mpa}$ & $877 \mathrm{Mpa}$ & $927 \mathrm{Mpa}$ \\
\hline 6 Jam & $959 \mathrm{Mpa}$ & $885 \mathrm{Mpa}$ & $902 \mathrm{Mpa}$ & $916 \mathrm{Mpa}$ & $809 \mathrm{Mpa}$ & $747 \mathrm{Mpa}$ \\
\hline
\end{tabular}

Dengan memperhatikan gambar 4 dapat diamati bahwa pada saat proses temperisasi dari suhu $600{ }^{0} \mathrm{C}, 650{ }^{0}$ $\mathrm{C}, 700{ }^{0} \mathrm{C}$ secara umum menurunkan sifat mekanik dari kekuatan tarik 1330 Mpa menjadi 989 Mpa pada suhu temerisasi $700{ }^{0} \mathrm{C}$ waktu 1 jam. Ini juga terjadi pada variasi waktu temperisasi 6 jam yaitu 959 Mpa menjadi 809 Mpa pada material AISI 410 Standart. Namun setelah di tambahkan 3 \% (Mo) mengalami peningkatan sifat mekanik gambar 4.3 (b) dari yang sebelumnya pada material standart 1330 Mpa menjadi 1350 Mpa mengalami peningkatan sifat mekanik. Sebab mengalami peningkatan kekuatan mekanik dari penambahan Mo $3 \%$ adalah terjadi pembentukan karbida logam molibdenum. Namun dengan proses tempering dari $600{ }^{0} \mathrm{C}, 650{ }^{0} \mathrm{C}, 700{ }^{0} \mathrm{C}$ dengan peningkatan variasi waktu yang semakin lama akan menurunkan sifat mekanik material dari 1 jam, 3 jam, 6 jam hasilnya $1330 \mathrm{Mpa}, 110 \mathrm{Mpa}$, 959 Mpa ini juga terlihat pada material modifikasi 1350 Mpa, 1080 Мpa, 885 Мpa.
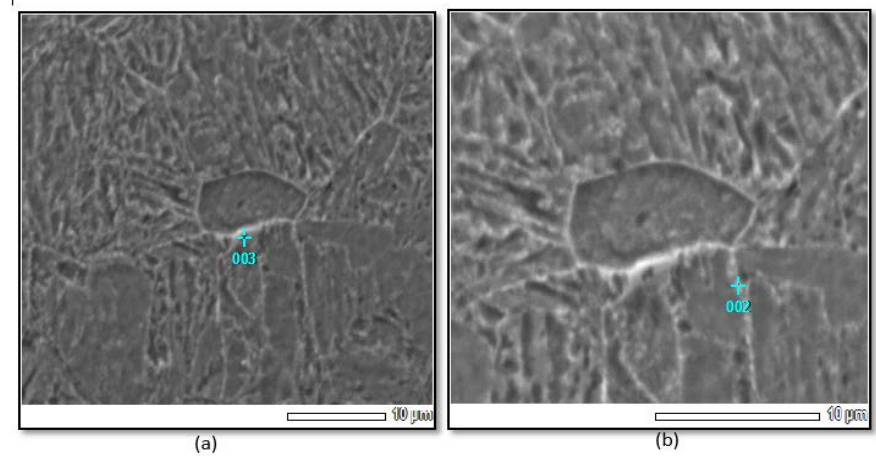

Gambar 3 Foto pengujian SEM untuk menganalisa unsur karbida logam pada baja AISI 410 Standar Etsa Kalling's austenisasi $1050{ }^{\circ} \mathrm{C}$ dengan proses tempering $650{ }^{\circ} \mathrm{C} 3$ jam didinginkan dengan udara. Pembesaran $3000 \mathrm{X}$ (a) dan pembesaran $5000 \mathrm{X}(\mathrm{b})$
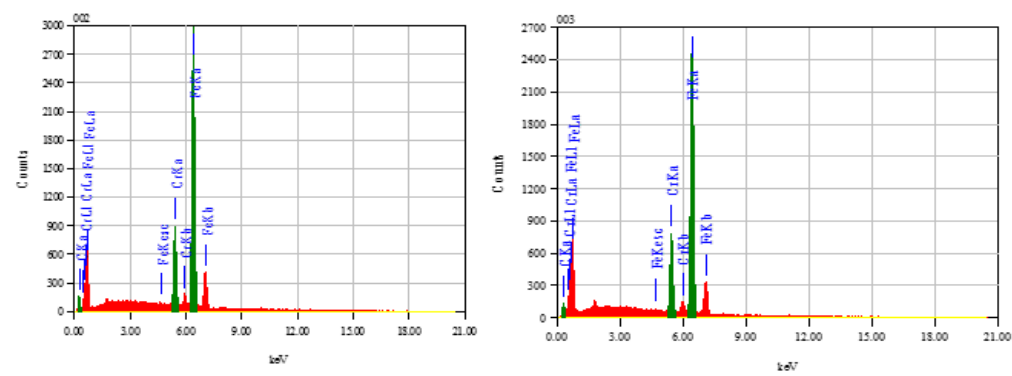

Gambar 4 Spektrum EDS unsur unsur didalam karbida mengamati karbida logam pada benda uji baja AISI 410 Standart Etsa Kalling's austenisasi $1050{ }^{\circ} \mathrm{C}$ dengan proses tempering $650{ }^{\circ} \mathrm{C} 3$ jam didinginkan dengan udara. 


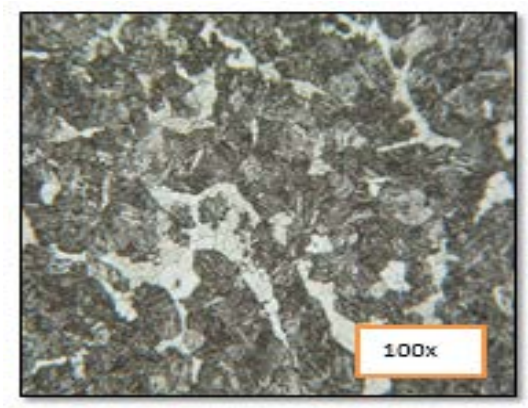

(a)

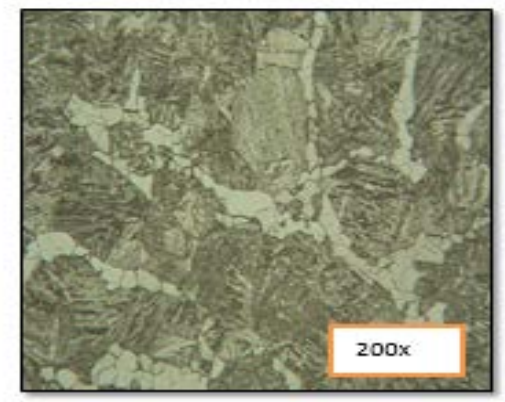

(b)

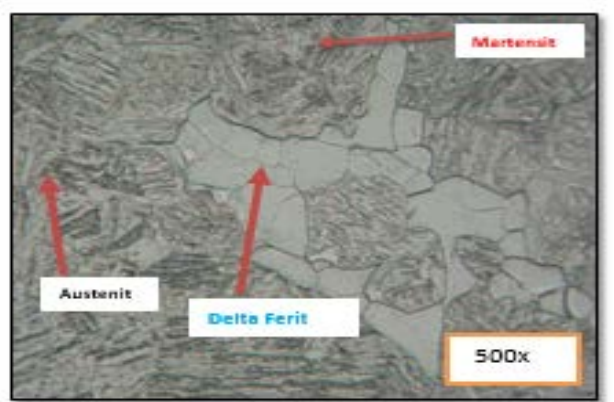

(c)

Gambar 2 Foto struktur mikro baja AISI 410 Modifikasi 3\% (Mo) yang dilakukan dengan Etsa Kalling’s pada austenisasi

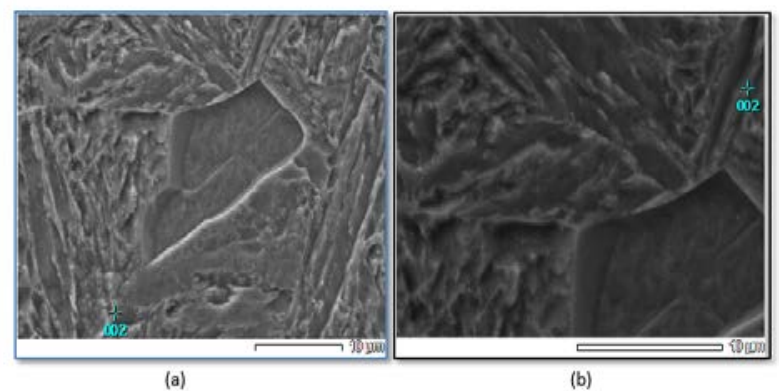

(b)

Gambar 5 Foto SEM untuk mengamati karbida loga pada baja ASTM 410 Modifikasi 3\% (Mo) Etsa Kalling’s austenisasi $1050{ }^{\circ} \mathrm{C}$ dengan proses Tempering $650{ }^{\circ} \mathrm{C} 3$ jam didinginkan dengan udara. . Pembesaran $3000 \mathrm{X}$ (a) dan pembesaran 5000 $\mathrm{X}(\mathrm{b})$
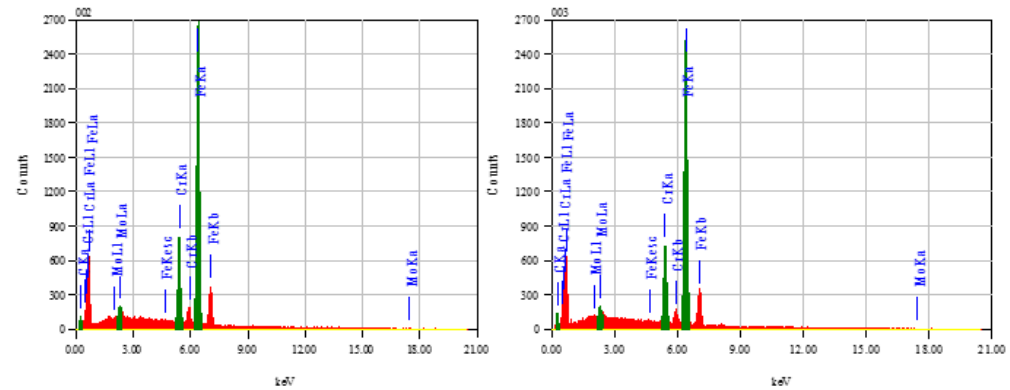

ISSN 2620-6706 
Gambar 6 Spektrum EDS unsur unsur didalam karbida mengamati karbida loga pada baja AISI 410 Modifikasi 3\% (Mo) Etsa Kalling's austenisasi $1050{ }^{\circ} \mathrm{C}$ dengan proses tempering $650{ }^{\circ} \mathrm{C} 3$ jam didinginkan dengan udara.

Gambar 3 dan 5 menunjukan foto mikroskop optik SEM baja tahan karat AISI 410 standart dan modifikasi penambahan Mo $3 \%$ setelah di austenisasi $1050{ }^{0} \mathrm{C}$ dan proses temperisasi selama 3 jam pada suhu $650{ }^{0} \mathrm{C}$. Secara umum dapat dilihat struktur mikro keduanya terdiri sebagian besar berupa fasa martensit. Fasa martensit terjadi pengurangan setelah dilakukan modifikasi penambahan unsur $3 \%$ Mo. Fasa ferit delta tampak lebih jelas pada baja AISI 410 modifikasi $3 \%$ Mo. Pembentukan ferrit delta juga dilaporkan pada peneliti sebelumnya dengan penambahan $1 \%$ Mo.

Gambar 4 dan 6 menunjukan foto mikroskop optik SEM baja tahan karat AISI 410 standart dan modifikasi penambahan Mo $3 \%$ setelah di austenisasi 1050 0 C dan proses tempering selama 3 jam pada suhu 6500 Celcius. Secara umum kedua hasil pengujian dapat disimpulkan bahwa senyawa karbida logam pada kedua sample memiliki kandungan unsur karbon yang mirip sekitar 11-25\% (atom) dan dapat dirumuskan sebagai senyawa M23C6.

Baja tersebut terdiri sebagian besar fasa martensit temper berbentuk bilah (lath), Karbida logam, austenisasi sisa dan fasa ferit delta. Fasa martensit temper terjadi pengurangan yang signifikan setelah dilakukan modifikasi penambahan unsur 3 \% Mo. Fasa ferit delta tampak lebih jelas pada baja AISI 410 modifikasi $3 \%$ Mo. Pembentukan ferit delta juga dilaporkan pada peneliti sebelumnya dengan penambahan $1 \%$ Mo.

Pada gambar 5 menunjukan fasa austenit sisa dengan jumlah dan bentuk yang tidak bisa ditentukan jumlahnya secara kuantutatif dari gambar tersebut . Namun secara kualitatif dapat dilihat dari gambar tersebut dari kerapatan fasa martensit yakni makin berkurang dengan penambahan unsur Mo. Gambar 3 dan 5 tampak bahwa karbida logam terlihat berbentuk seperti bintik bintik putih. Terdistribusi sangat merata di dalam fasa martensit dan austenit sisa. Sebagian unsur karbida juga tampak pada fasa ferit delta. Dengan menganalisa EDS terhadap karbida logam pada baja tanpa Mo dan penambahan Mo 3 \% menunjukan puncak unsur $\mathrm{Fe}$ dan $\mathrm{Cr}$ dengan intensitas sangat dominan. Kedua - keduanya memiliki kandungan senyawa karbon yang relatif sama sekita $0.27 \%$. Efek pembentukan karbida logam dengan penambahan Mo juga dilaporkan oleh peneliti lain ${ }^{[12]}$. Karbida logam inilah yang kemudian mempengaruhi kekuatan tarik yang lebih tinggi dibanding AISI 410 standart. Penambahan unsur Mo 3 \% meningkatkan sifat mekanik baja AISI 410 akibat terbentuk karbida logam yang terdistribusi merata.

\section{KESIMPULAN DAN SARAN}

Semakin lama proses tempering pada saat perlakuan panas menurunkan nilai kekerasan baja tahan karat AISI 410. Sebaliknya meningkatan sifat mekanik (kekuatan tarik dan kekuatan luluh).

1. Penambahan unsur 3\% Mo mengakibatkan meningkatnya kandungan fasa ferrit pada struktur mikro dan berakibat menurunkan sifat kekerasan baja Tipe AISI 410. Ditambahkan unsur 3 \% Mo dapat mengurangi kandungan crom di dalam karbida logam tersebut akibat subtitusi parsial Crom dengan Molibdenum.

2. Penambahan unsur Mo $3 \%$ meningkatkan sifat mekanik baja AISI 410 akibat terbentuk karbida logam yang terdistribusi merata diantara batas butir.

- Peneliti berikutnya sebaiknya melanjutkan penelitian dengan melakukan proses pembuatan uji Stress Corosiion Cracking pada material AISI 410 yang sudah di modifikasi penambahan 3 \% unsur Mo .

- Melakukan proses manufaktur pembuatan sudu turbin beserta simulasi kegagalan yang mungkin terjadi 


\section{DAFTAR PUSTAKA}

1. Borniadi, Marco a Asadrea Casaroli,"Stainless steels,”Dipartimento di Meccanica.

2. Mika Seitovirta, Handbok of Stainless Steel, Sweden,2013

3. Daryanto, Ilmu Metalurgy. Satu nusa, Bandung, Oktober 2010

4. Edin Supardi, Pengujian Logam, Angkasaa, Bandung, 1994

5. Anrinal, Metalurgi fisik, Andi, Padang, Februari 2013

6. Efendi Mabruri,Pengaruh Mo (Molibdenum) dan Ni (Nikel) Terhadap Struktur Mikro Baja Tahan Karat Martensitik 13 Cr.Majalah Metalurgi (2015) 3: 133-140 des-2015 